\title{
Surgical management of cardiac tamponade: Is left anterior minithoracotomy really safe and effective?
}

\author{
Mirko Barone*, Marco Prioletta, Giuseppe Cipollone, Decio Di Nuzzo, Pierpaolo Camplese, Felice Mucilli
}

Department of General and Thoracic Surgery, University Hospital of Chieti, Chieti, Italy

\author{
Received: 1 September 2016 \\ Accepted: 18 Novembr 2016 \\ Published online: 27 May 2017 \\ *Corresponding author: Mirko \\ Barone, MD; Department of Genera \\ and Thoracic Surgery, University \\ Hospital "SS. Annunziata" of Chieti, \\ Italy. \\ Phone: +390871358289 \\ Fax: +39 0871358220 ; \\ Email:mir87mb@libero.it \\ Competing interests: None. \\ Funding information: None \\ Citation: Barone M, Prioletta M \\ Cipollone G, Di Nuzzo D, Camplese \\ $P$, Mucilli F. Surgical management of \\ cardiac tamponade: Is left anterior \\ minithoracotomy really safe and \\ effective? Journal of Emergency \\ Practice and Trauma 2017; 3(2): 53- \\ 58. doi: 10.15171/jept.2017.04.
}

\begin{abstract}
Objective: Cardiac tamponade is a life-threatening clinical entity that requires an emergency treatment. Cardiac tamponade can be caused both by benign and malignant diseases. A variety of methods have been described for the treatment of these cases from needle-guided pericardiocentesis, balloon-based techniques to surgical pericardiotomy. The Authors report their experience in surgical management of cardiac tamponade and an exhaustive review of literature.

Methods: This study involved 61 patients ( 37 males and 24 females) with an average age of $61.80 \pm 16.32$ years. All patients underwent emergency surgery due to the presence of cardiac tamponade.

Results: Cardiac tamponade was caused by a benign disease in $57.40 \%$ of patients. In cancer patients group, lung cancer, breast cancer and malignant pleural mesothelioma were the most common neoplasms (17-27, 87\%). The average preoperative size of pericardial effusion at M-2D echocardiography was $30.15 \pm 5.87 \mathrm{~mm}$. Postoperative complications were observed in 11 patients (18\%). The reoperation rate was 3.3\% (2 patients) due to relapsed cardiac tamponade. 30-day mortality rate was 3.3\%. Overall cumulative survival was 29.9 \pm 20.1 months. Twenty-nine patients (47.5\%) died during the follow up period. By dividing the population into two groups, group $B$ (benign) and group $M$ (malignant), there was a statistically significant difference $(P<0.001)$ in terms of survival.

Conclusion: In conclusions, anterior minithoracotomy for surgical treatment of cardiac tamponade has to be held into account in patients both with benign diseases and malignancies.

Keywords: Cardiac tamponade, Minithoracotomy, Pericardial malignancies, Overall survival
\end{abstract}

\section{Introduction}

Cardiac tamponade is a life-threatening clinical entity that requires an emergency treatment (1). It is characterized by hemodynamic abnormalities resulting from an increased pericardial pressure due to the accumulation of fluid (serum, blood, chyle, pus) leading to a restriction of the filling rate, a reduction in stroke volume and cardiac output (2).

Cardiac tamponade can be caused by pericarditis (idiopathic, viral), iatrogenic injury (percutaneous procedures, post-CABG), thoracic trauma, neoplasms (thoracic and extrathoracic ones), uremia, cirrhosis, collagen diseases, vasculitis, systemic lupus erythematosus, tuberculosis, Dressler syndrome, aortic dissection, oozing ventricular, aortic or ventricular blow-out (3). The diagnostic triad of cardiac tamponade, or Beck's triad, is the reduction of arterial blood pressure, increased venous pressure and quiet heart (4). Clinical signs of cardiac tamponade include hypotension, tachycardia, pulsus paradoxus, increased jugular pressure (Kussmaul's sign), muffled heart sounds, decreased ECG voltages and increased cardiac silhouette on plain chest radiograph (2).

A variety of methods have been described for the treatment of these cases from needle-guided pericardiocentesis (5), balloon-based techniques to surgical pericardiotomy $(6,7)$, aiming to detention of cardiac compression and prevention of re-accumulation (8).

Surgical techniques are usually associated with a lower risk of recurrence, especially in cancer patients. In Literature, minimally invasive (video-assisted thoracoscopic pericardial window) and invasive surgical accesses (subxiphoid pericardiotomy, pericardiotomy via median sternotomy or via left anterior minithoracotomy) (9-11) are described.

\section{Methods}

This study involved 61 patients ( 37 males and 24 females) observed from 2010 to 2015 with an average age of 61.80 \pm 16.32 years (Table 1). All patients underwent emergency surgery due to the presence of cardiac tamponade. Diagnosis was clinical (arterial hypotension, tachycardia, dyspnoea, Kussmaul's sign, pulsus paradoxus) and radiographic (M- and 2D-mode echocardiography, computed 
tomography (CT) angiography of the chest). In our department, all patients undergo a preoperative CT angiography of the chest in order to exclude any myocardical or aortic bulb injury (ventricular blow out or oozing, lacerations of the coronary vessels). In fact, in the presence of these lesions, patient management is entrusted to cardiac surgeons.

All patients underwent routine blood chemistry and blood gas analysis in order to complete diagnostic iter. On account of the emergency, all patients with pericardial effusion with hemodynamic impairment were quickly sent for surgery, a pleuro-pericardial window. The surgical technique involves a $4-6 \mathrm{~cm}$ left anterior minithoracotomy at the fourth intercostal space with patient in 45 degrees left lateral decubitus position. The angle allows a better exposure of the pericardial sac. After opening the pleural cavity, an intrapleural pericardiotomy ahead the left phrenic nerve is done, allowing a gradual and cautious detension of the pericardial sac. At the end of the pericardial drainage, a $3 \times 3 \mathrm{~cm}$ piece of serous is picked up. The rationale is to perform a histological analysis of tissue and to pack an effective means between the pericardium and the left mediastinal pleura. After surgery, a chest drainage is placed. The average time of the intervention was $36 \pm$ 21 minutes.

All data are presented as means with standard deviations and their minimum and maximum values. Categorical variables are presented as absolute $(\mathrm{N})$ and percentage (\%). The analysis of survival was performed with the use of Kaplan and Meier's method with relative curves. These were compared with the method of logarithmic regression. $P$ values less than 0.05 were considered statistically significant.

\section{Results}

On admission, the cause of cardiac tamponade was unknown in most of patients (33-54, 10\%). In two patients, cardiac tamponade was the first sign of an unknown metastatic tumor disease (lung adenocarcinoma and cardiac lymphoma). In the remaining cases, cardiac tamponade was secondary to the presence of a tumor within or outside the chest (one patient with metastatic carcinoma of the penis) or to a thoracic trauma (3-4, 92\%).

Histologically, a benign disease was the cause of cardiac tamponade in $57.40 \%$ of patients (35 patients), such as refractory pericarditis $(26-43,33 \%)$, hydropericardium from decompensated cirrhosis or chronic renal insufficiency. In cancer patients group, lung cancer, breast cancer and malignant pleural mesothelioma were the most common neoplasms (17-27, 87\%). Also, mediastinal tumors (thymoma, lymphoma, synovial sarcoma) may cause secondary cardiac tamponade (Table 2).

The average preoperative size of the pericardial effusion at M-2D echocardiography was $30.15 \pm 5.87 \mathrm{~mm}$. However, the amount of pericardial effusion can not be correlated to the onset of cardiac tamponade; in fact, in our experience, we have seen cases of conspicuous pericardial effusion without hemodynamic impairment due to the onset of compensatory mechanisms such as pulmonary hypertension. The average hospital stay of the patients was $14.5 \pm 9.6$ days. The reason is to be found in patients' comorbidities and post-operative controls. In fact, all were echocardiographically screened (average postoperative pericardial effusion thickness: $3.8 \pm 5.4 \mathrm{~mm}$ ) and only, in the presence of resolution of the pericardial effusion, chest tube was removed (average time: $10.4 \pm 6.4$ days) (Table 1).

Postoperative complications were observed in $18 \%$ of

Table 1. General population characteristics

\begin{tabular}{lcc}
\hline Drugs & No. & Percent \\
\hline Sex & & \\
$\quad$ Male & 37 & 60.70 \\
$\quad$ Female & 24 & 39.30 \\
Age & 61.80 & $(18-94)$ \\
Hospital stay & $14.5 \pm 9.6$ & $(6-60)$ \\
\hline Preoperative fluid collection width & $30.15 \pm 5.87$ & $(18.00-42.00)$ \\
\hline Postoperative fluid collection & $3.8 \pm 5.4$ & $(0.00-33.00)$ \\
width & $10.4 \pm 6.4$ & $(4.00-45-00)$ \\
Chest drain permanence & 11 & 18.00 \\
Complications ${ }^{\mathrm{a}}$ & 2 & 3.30 \\
\hline Re-do surgery & 2 & 3.30 \\
\hline Perioperative death & $29.90 \pm 20.10$ & $(0.00-67.00)$ \\
\hline Cumulative OS & & \\
$\quad$ Group B & $58.4 \pm 2.88$ & \\
Group M & $15.94 \pm 2.93$ & \\
\hline Death & 29 & 47.5 \\
Disease-related death & 22 & 36.1 \\
\hline
\end{tabular}

a 4 patients atrial fibrillation, 2 patients ventricular fibrillation, 2 patients relapsed cardiac tamponade, 2 patients respiratory failure, 1 patient anemia.

${ }^{\mathrm{b}} \mathrm{P}<0.001$.

Table 2. Cardiac tamponade etiology

\begin{tabular}{lcc}
\hline & No. & Percent \\
\hline Etiology & 35 & \\
Benign & 26 & 42.60 \\
Malignant & & \\
Disease & 12 & 19.70 \\
Chronic pericarditis & 6 & 9.80 \\
Pulmonary adenocarcinoma & 5 & 8.20 \\
Pulmonary squamous carcinoma & 3 & 4.90 \\
Breast cancer & 3 & 4.90 \\
Malignant pleural mesothelioma & 5 & 8.20 \\
Hydropericardium & 1 & 1.60 \\
Cardiac lymphoma & 3 & 4.90 \\
Non Hodgkin lymphoma & 1 & 1.60 \\
Penis cancer & 14 & 23.00 \\
Acute pericarditis & 3 & 4.90 \\
Thymoma & 3 & 4.90 \\
Thoracic trauma & 1 & 1.60 \\
Synovial sarcoma & 1 & 1.60 \\
Chylopericardium & & \\
\hline
\end{tabular}


patients (11 patients). Most cases were cardiac complications (atrial fibrillation, ventricular fibrillation, relapsed cardiac tamponade). Two cases of respiratory failure and one of anemia were also recorded. In our experience, there was no mention of post-operative cardiac herniations secondary to the pericardial window procedure.

The reoperation rate was $3.3 \%$ (2 patients) due to relapsed cardiac tamponade. In one case, the second surgical access was a median sternotomy.

Although packing a pleuro-pericardial window represents a surgical emergency, the 30-day mortality rate was only $3.3 \%$ (2 patients).

All patients observed from 2010 to 2015 were subjected to follow-up. Overall cumulative survival of the general population was $29.90 \pm 20.10$ months. Twenty-nine patients (47.5\%) died during the follow up period. In 22 (75.87\%) of these, death was due to the same disease causing the episode of cardiac tamponade. By dividing the population into two groups, group $B$ (benign) and group $M$ (malignant) there was a statistically significant difference $(P<0.001)$ in terms of survival. In fact, an average of 58.4 \pm 2.88 (95\% CI: 52.72 to 64.04$)$ months was reported for group B patients and an average of $15.94 \pm 2.93$ (95\% CI: 33.96 to 47.96 ) months for group M patients, respectively (Figure 1). This discrepancy is mainly due to the etiology of cardiac tamponade. In cancer patients, this hemodynamic manifestation could be the evolution of metastatic disease characterized by a poor and a dismal prognosis.

\section{Discussion}

Cardiac tamponade is a life-threatening clinical entity that may result in a rapidly fatal cardiogenic shock (1). Presentation of cardiac tamponade can range from a minimally symptomatic effusion to a state of complete cardiovascular decompensation. In fact, it may be silent (echocardiographic tamponade), may present with classic symptoms, Beck's triad (4) (clinical tamponade), or may be the cause of a hemodynamic collapse (terminal tamponade). The first two represent the most common conditions and, as

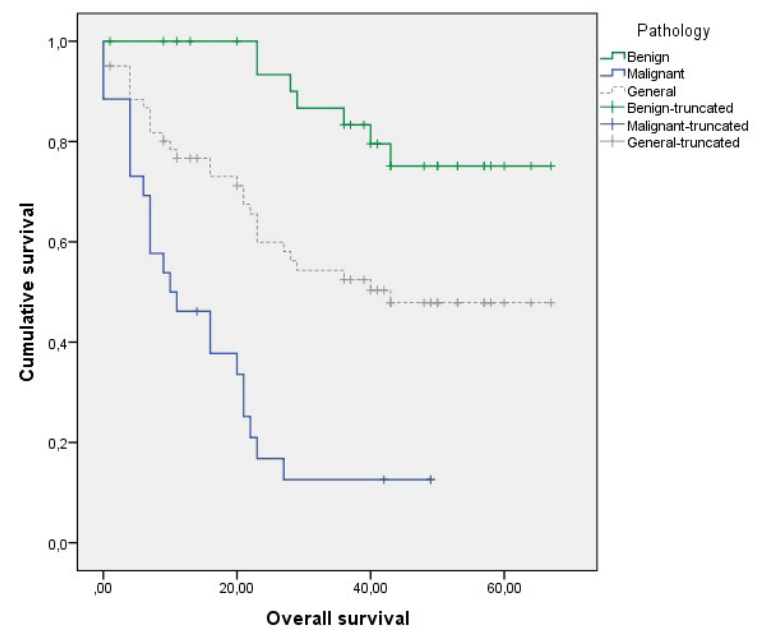

Figure 1. Probability of survival after cardiac tamponade (group B vs. group M). reported by Tsang et al, they reach a percentage higher than $90 \%$ (5). Cardiac tamponade is associated with widespread low electrocardiographic voltages (12) due to changes in the electro-mechanical pulse and diffusion abnormalities of body impedance (13). These findings (low QRS complexes) recover up to $81 \%$ of cases $(14,15)$ (Figure 2). Echocardiography is the main diagnostic test for the diagnosis of cardiac tamponade. The examination, performed in $\mathrm{M}$ - and 2D-mode, allows to evaluate the effusion thickness, the cardiac kinesis and indirect signs of hemodynamic dysfunction (Figure 3).

Cardiac tamponade can be caused by pericarditis (idiopathic, viral), iatrogenic injury (percutaneous procedures, post-CABG), thoracic trauma, neoplasms (thoracic and extrathoracic ones), uremia, cirrhosis, collagen diseases, chilopericardium (16), vasculitis, systemic lupus erythematosus (17), tuberculosis, hypothyroidism $(18,19)$, Dressler syndrome, aortic or coronaric dissection (20), ventricular oozing, aortic or ventricular blow-out (3).

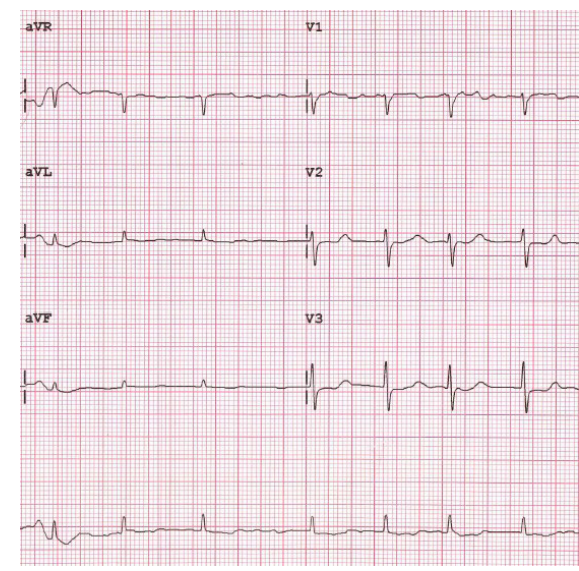

Figure 2. Cardiac tamponade: ECG findings (our personal case).

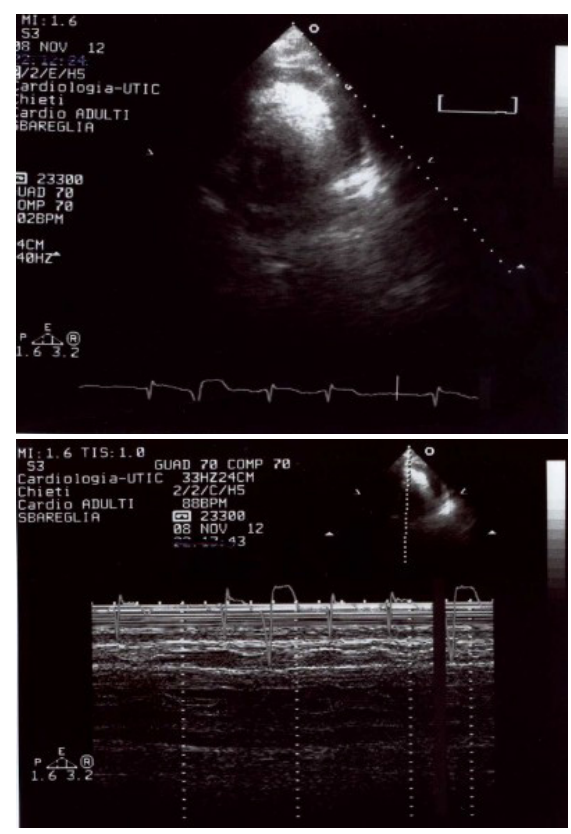

Figure 3. Cardiac tamponade: Echocardiographic findings (our personal case). 
Allen et al (21), in a series of patients with cardiac tamponade, reported that more than $60 \%$ of the cases were from cancer, while the remaining from inflammatory processes and uremic states.

In our study, data seem to be in slight contrast. In fact, $57.40 \%$ of cases were due to benign diseases (chronic or acute refractory pericarditis), while the remainings from neoplasms. Among these latters, lung cancer (squamous cell carcinoma and adenocarcinoma) was the predominant one (18.0\%), followed by malignant pleural mesothelioma, breast cancer and mediastinal tumors.

However, our results are confident with Literature, since more than half of secondary neoplasms of the pericardium are to be referred to lung cancer and breast cancer. The actual incidence of pericardial and myocardial metastatic diseases varies between $1 \%$ and $18 \%$ of all cancers (22).

Pericardial effusions are less common than pleural ones in cancer patients; although, their acute onset may rapidly deteriorate clinical conditions and significantly influence on prognosis.

Cardiac tamponade is a hemodynamic emergency that requires a rapid and timely intervention. But what is the gold standard of treatment is a discussed issue today. A variety of methods have been described from the needleguided pericardiocentesis (5), balloon-based techniques to surgical pericardiotomy $(6,7)$.

Needle-guided pericardiocentesis, considered the standard of treatment, is a rapid method for drainage. It may be adopted in hemodynamically unstable patients, in intensive care units or in patients who are unsuitable for surgery due to poor clinical conditions. It is well-tolerated in all age groups, including children (23), and it can be quickly performed in unstable patients to relieve symptoms (24). Moreover, it presents low mortality, low complications, but high recurrence rates.

Pericardiocentesis is life-saving and it is indicated for 20 $\mathrm{mm}$ or more effusions (diastolic width). The most dangerous complications are myocardial or coronaric lacerations but safety has been implemented with the adoption of echocardiographic or fluoroscopic guidance.

Maisch et al (25), in the European Society of Cardiology guidelines, reported major complication rates of about $1.3 \%-1.6 \%$. Among these, cardiac perforations (0.9\%) and arrhythmias $(0.6 \%)$ are the most recurrent. Minor complications include pneumothorax, vasovagal response with transient hypotension, non-sustained supraventricular tachycardia and pleuropericardial fistula $(5,26)$. Procedure-related mortality is low $(<1 \%)$, while overall complications may vary from $4 \%$ to $20 \%(27,28)$. At the same time, Kopecky et al (29) and Celermajer et al (30) reported recurrence rates ranging from $19 \%$ to $24 \%$. Finally, the procedure also allows to leave pericardial indwelling catheters for drainage or for locoregional chemotherapy (31-33).

Surgical procedures for pericardial drainage are: subxifoid pericardial window, transthoracic pericardial window (left anterior submammary minithoracotomy) and pericardiotomy via median sternotomy. The potential advantages of a surgical approach are direct visualization, exploration of the entire pericardium, a complete drainage, biopsy of the pericardium for histological examination and the placement of a larger caliber drainage $(34,35)$.

Subxifoid pericardial window is simple and reproducible (36). Kurimoto et al (37) also proposed the opportunity to perform a blind finger-assisted subxifoid pericardiotomy, highlighting the good efficacy of the procedure.

Video-assisted thoracoscopic pericardial window has many advantages: minor trauma, the ability to perform wider pericardial resections, the best visualization of anatomical structures and the possibility of posterior pericardial collection drainage (38). Muhammad (39) reported no intra and postoperative complications and mortality. Also, Georghiou et al (40) described no peri-procedural complications, but video-assisted surgery is still contraindicated in patients with impaired respiratory function contraindicating single-lung ventilation (9). In addition, pediatric cases with thoracoscopic access have been described (41,42). A modified video-assisted thoracoscopy technique was described by Monaco et al (43).

The creation of a pericardial window (subxifoid or transthoracic) is preferable in cancer patients in order to allow a permanent drainage. Our choice to perform a transthoracic pericardial window through a minithoracotomy finds comfort with papers in Literature. Olsen et al (44) believe the procedure is quick and simple. No cases of intra- or postoperative deaths are reported. Gregory et al (45), however, reported a mortality rate of $8 \%$. Transthoracic surgery is rapid and it does not require a selective pulmonary intubation (Carlens' or Robertshaw's tube), as opposed for video thoracoscopic access, which could lead to the onset of a hemodynamic overload or a tachyarrhythmia due to selective intubation. In our study, we observed an overall mortality rate of $3.3 \%$ (one case of cardiac lymphoma and one case of malignant pleural mesothelioma); eithers due to the onset of electro-mechanical cardiac complications (ventricular fibrillation). Morbidity rate of $11.74 \%(7 / 11)$ in cancer patients. Celik et al (46) reported a median overall survival of $10.41 \pm 1.79$ months for cancer patients, while in our study we observed a survival rate of $15.94 \pm 3.86$. In addition, we observed a low recurrence rate $(3.3 \%)$, one in a cancer patient, and this data is significantly lower than those reported in literature both for pericardiocentesis and surgical cases. Regarding these cases, we believe the origin is to be found in the rapid establishment of post surgical adhesions leading to an altered drainage and therefore a failure of the pericardial window. Both episodes occurred within 30 days after surgery suggesting the onset of a post pericardiotomy syndrome. This clinical entity is classified as a specific form of iatrogenic or traumatic pericarditis and it is characterized by recurrent post surgical pericardial effusion. The syndrome is usually self-limited and it presents a variable incidence from $1 \%$ to $17.8 \%(47,48)$. Nishimura et al believe that causes are due to immune factors interfering with host response (49). 


\section{Conclusion}

In conclusion, we believe the transthoracic surgical treatment of cardiac tamponade has to be held into account in patients both with benign diseases and malignancies. Our results, in terms of perioperative morbidity and mortality, are quite comparable to patients undergoing minimally invasive or percutaneous procedures. Moreover, low mortality and recurrence rates demonstrate pericardial window via anterior minithoracotomy can be considered a safe and effective method in the treatment of cardiac tamponade.

\section{Authors' contributions}

All authors contributed to data collection, text arrangement and study design.

\section{Ethical issues}

The article does not contain any research with human participants performed by the authors. For this type of study, no formal consent was required. It is an anonymous one.

\section{References}

1. Sagristà-Sauleda J, Mercé AS, Soler-Soler J. Diagnosis and management of pericardial effusion. World J Cardiol 2011; 3(5): 135-43. doi: 10.4330/wjc.v3.i5.135.

2. Seferović PM, Ristić AD, Imazio M, Maksimović R, Simeunović D, Trinchero R, et al. Management strategies in pericardial emergencies. Herz 2006; 31(9): 891-900. doi: 10.1007/s00059-006-2937-0.

3. LeWinter MM, Tischler MD. Pericardial diseases. In: Bonow RO, Mann DL, Zipes DP, Libby P, eds. Braunwald's Heart Disease: A Textbook of Cardiovascular Medicine. 9th ed. Philadlephia, PA: Saunders Elsevier; 2011.

4. Beck CS. Two cardiac compression triads. JAMA 1935; 104 (9): 714-6. doi: 10.1001/jama.1935.02760090018005.

5. Tsang TS, Enriquez-Sarano M, Freeman WK, Barnes ME, Sinak LJ, Gersh BJ, et al. Consecutive 1127 therapeutic echocardiographically guided pericardiocenteses: clinical profile, practice patterns, and outcomes spanning 21 years. Mayo Clin Proc 2002; 77(5): 429-36. doi: 10.4065/77.5.429.

6. Vaitkus PT, Herrmann HC, LeWinter MM. Treatment of malignant pericardial effusion. JAMA 1994; 272(1): 59-64. doi: 10.4065/77.5.429.

7. Swanson N, Mirza I, Wijesinghe N, Devlin G. Primary percutaneous balloon pericardiotomy for malignant pericardial effusion. Catheter Cardiovasc Interv 2008; 71(4): 504-7. doi: 10.1002/ccd.21431.

8. Mercé J, Sagristà-Sauleda J, Permanyer-Miralda G, SolerSoler J. Should pericardial drainage be performed routinely in patients who have a large pericardial effusion without tamponade? Am J Med 1998; 105(2): 106-9. doi: 10.1016/ s0002-9343(98)00192-2.

9. Georghiou GP, Stamler A, Sharoni E, Fichman-Horn S, Berman M, Vidne BA, et al. Video-assisted thoracoscopic pericardial window for diagnosis and management of pericardial effusions. Ann Thorac Surg 2005; 80(2): 607-10. doi: 10.1016/j.athoracsur.2005.02.068.

10. Fortuño Andrés JR, Alguersuari Cabiscol A, Falcó Fages J, Castañer González E, Bermudez Bencerrey P. Radiological approach to cardiac tamponade. Radiologia 2010; 52(5): 414-24. doi: 10.1016/j.rx.2010.05.011. [In Spanish].
11. Liberman M, Labos C, Sampalis JS, Sheiner NM, Mulder DS. Ten-year surgical experience with nontraumatic pericardial effusions: a comparison between the subxyphoid and transthoracic approaches to pericardial window. Arch Surg 2005; 140(2): 191-5. doi: 10.1001/archsurg.140.2.191.

12. Eisenberg MJ, de Romeral LM, Heidenreich PA, Schiller NB, Evans GT Jr. The diagnosis of pericardial effusion and cardiac tamponade by 12-lead ECG. A technology assessment. Chest 1996; 110(2): 318-24. doi: 10.1378/ chest.110.2.318.

13. Karatay CM, Fruehan CT, Lighty GW Jr, Spear RM, Smulyan H. Acute pericardial distension in pigs: effect of fluid conductance on body surface electrocardiogram QRS size. Cardiovasc Res 1993; 27(6): 1033-8. doi: 10.1093/ cvr/27.6.1033.

14. Bruch C, Schmermund A, Dagres N, Bartel T, Caspari $\mathrm{G}$, Sack $\mathrm{S}$, et al. Changes in QRS voltage in cardiac tamponade and pericardial effusion: reversibility after pericardiocentesis and after anti-inflammatory drug treatment. J Am Coll Cardiol 2001; 38(1): 219-26. doi: 10.1016/s0735-1097(01)01313-4.

15. Gumrukcuoglu HA, Odabasi D, Akdag S, Ekim H. Management of cardiac tamponade: a comperative study between echo-guided pericardiocentesis and surgery-a report of 100 patients. Cardiol Res Pract 2011; 2011: 197838. doi: 10.4061/2011/197838.

16. Barbetakis N, Asteriou C, Konstantinou D, Giannoglou D, Tsilikas C, Giannoglou G. Spontaneous chylous cardiac tamponade: a case report. J Cardiothorac Surg 2010; 5: 11. doi: 10.1186/1749-8090-5-11.

17. Maharaj SS, Chang SM. Cardiac tamponade as the initial presentation of systemic lupus erythematosus: a case report and review of the literature. Pediatr Rheumatol Online J 2015; 13: 9. doi: 10.1186/s12969-015-0005-0.

18. Hellmann AR, Kostro J, Dziedzic R, Hellmann M, Dudziak M. Cardiac tamponade as the first manifestation of primary hypothyroidism. Kardiol Pol 2015; 73(9): 786. doi: 10.5603/ kp.2015.0168.

19. Sinha A, Yeruva SL, Kumar R, Curry BH. Early cardiac tamponade in a patient with postsurgical hypothyroidism. Case Rep Cardiol 2015; 2015: 310350. doi: 10.1155/2015/310350.

20. Goh AC, Lundstrom RJ. Spontaneous coronary artery dissection with cardiac tamponade. Tex Heart Inst J 2015; 42(5): 479-82. doi: 10.14503/THIJ-14-4260.

21. Allen KB, Faber LP, Warren WH, Shaar CJ. Pericardial effusion: subxiphoid pericardiostomy versus percutaneous catheter drainage. Ann Thorac Surg 1999; 67(2): 437-40. doi: 10.1016/s0003-4975(98)01192-8.

22. Gassman HS, Meadows R, Baker LA. Metastatic tumors of the heart. Am J Med 1955; 19(3): 357-65. doi:10.1016/00029343(55)90124-8.

23. Tsang TS, El-Najdawi EK, Seward JB, Hagler DJ, Freeman WK, O'Leary PW. Percutaneous echocardiographically guided pericardiocentesis in pediatric patients: evaluation of safety and efficacy. J Am Soc Echocardiogr 1998; 11(11): 1072-7. doi: 10.1016/s0894-7317(98)70159-2.

24. Fitch MT, Nicks BA, Pariyadath M, McGinnis HD, Manthey DE. Videos in clinical medicine. Emergency pericardiocentesis. N Engl J Med 2012; 366(12): e17. doi: 10.1056/nejmvcm0907841.

25. Maisch B, Seferović PM, Ristić AD, Erbel R, Rienmüller R, Adler Y, et al. Guidelines on the diagnosis and management 
of pericardial diseases executive summary; The Task force on the diagnosis and management of pericardial diseases of the European society of cardiology. Eur Heart J 2004; 25(7): 587-610. doi: 10.1016/j.ehj.2004.02.002.

26. Wong B, Murphy J, Chang CJ, Hassenein K, Dunn M. The risk of pericardiocentesis. Am J Cardiol 1979; 44(6): 11104.

27. Ainsworth CD, Salehian O. Echo-guided pericardiocentesis: Let the bubbles show the way. Circulation 2011; 123(4): e210-1. doi: 10.1161/circulationaha.110.005512.

28. Fejka M, Dixon SR, Safian RD, O'Neill WW, Grines CL, Finta B, et al. Diagnosis, management, and clinical outcome of cardiac tamponade complicating percutaneous coronary intervention. Am J Cardiol 2002; 90(11): 1183-6. doi: 10.1016/s0002-9149(02)02831-x.

29. Kopecky SL, Callahan JA, Tajik AJ, Seward JB. Percutaneous pericardial catheter drainage: report of 42 consecutive cases. Am J Cardiol 1986; 58(7): 633-5. doi: 10.1016/00029149(86)90290-0.

30. Celermajer DS, Boyer MJ, Bailey BP, Tattersall MH. Pericardiocentesis for symptomatic malignant pericardial effusion: a study of 36 patients. Med J Aust 1991; 154(1): 19-22.

31. Tanaka Y, Tsuboi K, Yamamoto A, Tsuda S, Tsujii S, Yagi $\mathrm{K}$, et al. Long-term survival of a breast cancer patient with carcinomatous pleuritis and carcinomatous cardiac tamponade successfully treated by multimodality therapy. Gan To Kagaku Ryoho 2015; 42(4): 489-92. [In Japanese].

32. Lestuzzi C, Berretta M, Tomkowski W. 2015 update on the diagnosis and management of neoplastic pericardial disease. Expert Rev Cardiovasc Ther 2015; 13(4): 377-89. doi: 10.1586/14779072.2015.1025754.

33. Sun T, Zhang Y, Shen Y, Hu K, Zuo M. A case of advanced lung cancer with malignant pericardial effusion treated by intrapericardial Cinobufacini injection instillation. Biosci Trends 2014; 8(4): 235-9. doi: 10.5582/bst.2014.01073.

34. McDonald JM, Meyers BF, Guthrie TJ, Battafarano RJ, Cooper JD, Patterson GA. Comparison of open subxiphoid pericardial drainage with percutaneous catheter drainage for symptomatic pericardial effusion. Ann Thorac Surg 2003; 76(3): 811-5. doi: 10.1016/s0003-4975(03)00665-9.

35. Buchanan CL, Sullivan VV, Lampman R, Kulkarni MG. Pericardiocentesis with extended catheter drainage: an effective therapy. Ann Thorac Surg 2003; 76(3): 817-20. doi: 10.1016/s0003-4975(03)00666-0

36. Watarida S, Shiraishi S, Matsubayashi K, Imura M, Nishi T. Pericardial-peritoneal window for chronic exudative pericarditis using a subxiphoidal approach: report of three cases. Surg Today 2002; 32(5): 410-3. doi: 10.1007/ s005950200064.

37. Kurimoto Y, Hase M, Nara S, Yama N, Kawaharada N,
Morishita K, et al. Blind subxiphoid pericardiotomy for cardiac tamponade because of acute hemopericardium. J Trauma 2006; 61(3): 582-5. doi: 10.1097/01. ta.0000236060.37952.ce

38. Uramoto H, Hanagiri T. Video-assisted thoracoscopic pericardiectomy for malignant pericardial effusion. Anticancer Res 2010; 30(11): 4691-4.

39. Muhammad MI. The pericardial window: is a videoassisted thoracoscopy approach better than a surgical approach? Interact Cardiovasc Thorac Surg 2011; 12(2): 174-8. doi: 10.1510/icvts.2010.243725.

40. Georghiou GP, Porat E, Fuks A, Vidne BA, Saute M. Videoassisted pericardial fenestration for effusions after cardiac surgery. Asian Cardiovasc Thorac Ann 2009; 17(5): 480-2. doi: 10.1177/0218492309348505.

41. Pérez-Etchepare E, Al Makki A, Varlet F, López M. Thoracoscopic treatment in pericardial tamponade. Cir Pediatr.2012; 25(3): 166-8.

42. Agrawal V, Saxena A, Sethi A, Acharya H, Sharma D. Thoracoscopic pericardiotomy for management of purulent pneumococcal pericarditis in a child. Asian J Endosc Surg 2012; 5(3): 145-8. doi: 10.1111/j.1758-5910.2011.00129.x.

43. Monaco F, Barone M, David A, Risitano DC, Lentini S. Cardiac tamponade: a modified video-assisted thoracoscopic approach. Chir Ital 2009; 61(3): 321-6. [In Italian].

44. Olsen PS, Sørensen C, Andersen HO. Surgical treatment of large pericardial effusions. Etiology and long-term survival. Eur J Cardiothorac Surg 1991; 5(8): 430-2. doi: 10.1016/1010-7940(91)90189-q.

45. Gregory JR, McMurtrey MJ, Mountain CF. A surgical approach to the treatment of pericardial effusion in cancer patients. Am J Clin Oncol 1985; 8(4): 319-23.

46. Celik S, Celik M, Aydemir B, Tanrıkulu H, Okay T, Tanrikulu N. Surgical properties and survival of a pericardial window via left minithoracotomy for benign and malignant pericardial tamponade in cancer patients. World J Surg Oncol 2012; 10: 123. doi: 10.1186/1477-7819-10-123.

47. Kuvin JT, Harati NA, Pandian NG, Bojar RM, Khabbaz KR. Postoperative cardiac tamponade in the modern surgical era. Ann Thorac Surg 2002; 74(4): 1148-53. doi: 10.1016/ s0003-4975(02)03837-7.

48. Miller RH, Horneffer PJ, Gardner TJ, Rykiel MF, Pearson TA. The epidemiology of the postpericardiotomy syndrome: a common complication of cardiac surgery. Am Heart J 1988; 116(5 Pt 1): 1323-9. doi: 10.1016/0002-8703(88)90457-7.

49. Nishimura RA, Fuster V, Burgert SL, Puga FJ. Clinical features and long-term natural history of the postpericardiotomy syndrome. Int J Cardiol 1983; 4(4): 443-50. doi: 10.1016/0167-5273(83)90194-8. 